\title{
A Longitudinal Journey with BYOD Classrooms: Issues of Access, Capability and Outcome Divides
}

\author{
Janak Adhikari \\ Open Polytechnic \\ New Zealand \\ janak.mailbox@gmail.com
}

\section{Anuradha Mathrani}

Institute of Natural and Mathematical Sciences

Massey University

New Zealand

\section{Chris Scogings}

Institute of Natural and Mathematical Sciences

Massey University

New Zealand

\section{Abstract}

Bring Your Own Devices (BYOD) classrooms is the latest addition to the ongoing quest for transforming pedagogical practices and driving educational development outcomes. Governments and policymakers around the world are embracing the idea of integrating digital learning technologies into educational settings backed by research on the benefits offered like the lifelong development of individual learners. While technological interventions open up unlimited possibilities for accessing information and improving collaboration, thereby engaging learners with more interactive learning activities, a new type of gap between individuals could also take shape as the penetration of technologies and adoption stages advance. Results from past projects of similar nature within educational settings have indicated the possible rise in the gap among individuals based on digital access (i.e., equity in access/ownership of digital learning technologies), digital capability (i.e., equity in digital/information literacy skills and usage) and digital outcome (i.e., equity in knowledge acquisition and progression).

Therefore, we have conducted a longitudinal study to investigate a BYOD initiative by a New Zealand School. This study shares rich insights in the context of technology-mediated pedagogies and specifically BYOD classroom, as to how digital divides moved beyond access and skills to ensure inclusive learning outcomes. As a part of the five-year study of the technology-mediated teaching and learning initiative, we have been able to explain some of the unanswered questions around the issue of digital divides in the learning process. We investigated issues pertaining to digital divide in the context of BYOD classrooms to make the following revelations. First, the BYOD classroom initiative did not end up accentuating existing gaps in access to digital tools and technologies, despite earlier studies indicating towards increase in gaps. Second, our analysis strongly indicated the changing nature of digital divides with the presence of gaps in terms of information literacy and critical thinking ability, as the BYOD classroom progressed to mature stage. This was eventually bridged in the later stage, as students slowly adjusted to the classroom curricular structures in the BYOD classroom. Third, learner self-efficacy has been identified as a determinant of learning outcomes. In the earlier phase of ICT adoption, learner self-efficacy is influenced by a combination of information literacy, critical thinking ability, and positive motivation; however subsequently, self-efficacy influences affordances in various aspects of social cognitive abilities related to individual's learning activities affecting how learners engage and apply technology to achieve learning outcomes.

Keywords: BYOD, schools, digital access divide, digital capability divide, digital outcome divide 


\section{Introduction}

During the late 1990s, innovations in the information and communication technologies disrupted the traditional way of life introducing many opportunities and services people never imagined. Modern developments in digital technologies marked the beginning of the information age (Sterling, 1997) and revolutionized our working lives by enabling better access to information, ability to transfer and share information quickly, and improving communication and collaboration between individuals. This marked the start of a shift in the economy from traditional industry to an economy based on the information, i.e., an information society. However, despite the potential benefits offered by the information society and the increased penetration of digital technologies in society, not everyone around us has the same privilege of using the services offered by digital technologies, thereby restricting opportunities in the information society for some. That includes the inability to access, operate, and use the digital tools and technologies meaningfully to benefit from it. As a result, many individuals and societal groups are still facing digital exclusion from the rest of the population. Nonetheless, digital revolution has helped transform the society positively with many technology-driven services and opportunities despite challenges around the equity.

With the increased ubiquity of digital technologies into almost every aspect of our lives, the need for appropriate digital and information literacy skills are on the rise. In this changing technological world, digital skills are now considered as the third most important life skill alongside numeracy and literacy (DfES, 2003; Johnson, Levine, Smith, \& Stone, 2010). Therefore, there is a common consensus among educators and policy makers that the integration of digital tools and technologies into pedagogical practices has a lot to offer to improve the quality and changing needs of the education. One example of the facilitation of better technological infrastructure resulted from a government policy is the ultrafast broadband (UFB) initiative in New Zealand, which prioritized and mandated connectivity to education sectors (Parsons, 2016). One of the aims of the UFB initiative is to bring the school curriculum up to speed with digital learning using the supporting broadband infrastructure. A great deal of transformation is possible in teaching and learning methods through innovation in pedagogical practices, facilitated by modern digital technologies. On one side, the digital learning technologies has opened up the unlimited possibility for access to information, ease of handling and processing information, and improved collaboration opportunities resulting in ever-improving academic activities and results. Whereas on the other side, as the penetration of technologies and adoption stages in teaching and learning advances, the digital gap between the individual learners takes shape, which has been conceptualised in a research paper with a three level digital divide framework (Wei, Teo, Chan, \& Tan, 2011).

Literature suggests that despite the potential of innovative learning technologies to improve learning outcomes; it could end up accentuating existing digital divides (Parr \& Ward, 2005; Rivers \& Rivers, 2004; Winter, 2004) within the current teaching and learning environments. The findings from the study of the digital opportunities pilot projects (DigiOps) ${ }^{1}$ indicate that these projects have failed to contribute as were expected from them. In some cases, the initiative designed to fill the gap of digital divide potentially caused the gap to become even wider, challenging the objective of any such technology-mediated teaching and learning initiatives in future. Supporting the earlier argument, Wei et al. (2011) too caution that as adoption stages of ICTs advance, there may arise more levels of digital divides based on the equity of information literacy and learning outcomes.

We have used the results from the digital opportunities pilot projects as the base to start our investigation into the digital divide phenomenon. . We selected a case of a secondary school in New Zealand, which made a decision to transform into technology-mediated teaching and learning, dubbed as the bring your own devices (BYOD) initiative. We focused the initial phase of our study to confirm the results from the digital opportunities projects. In the first year of

\footnotetext{
${ }^{1}$ The digital opportunities pilot projects (DigiOps) are partnerships between schools, organizations
} involved in ICT and the Ministry of Education in New Zealand. 
our study (during 2012 and 2013), our inquiry revealed issues related to digital access (i.e., equity in terms of the access/ownership of digital learning technologies among learners) and competency of using technologies available for meaningful learning activities (i.e., digital skills). Our initial results also took account of public opinion, which had earlier shown strong resistance to the school's initiative. These initial results provided a baseline to move the study forward. However, as the BYOD initiative gained momentum (leading up to the middle of 2014), there was much acceptance for technology-mediated teaching and learning among all the stakeholders, including students, teachers, and parents.

The goal of the technology-mediated teaching and learning initiatives is to improve studentlearning outcome, leveraging the opportunities provided by the digital learning technologies. Studies on what effect the technology-mediated teaching and learning will have on the existing digital divides, and how this may influence the digital outcomes of the learners subsequently is not currently present in the literature. With the increased penetration of digital technologies into the classroom teaching and learning practices like BYOD classrooms, studies on how the existing and new digital divides evolve are needed.

This study therefore investigates beyond digital access and skills, as the BYOD initiative progressed into mature stages (i.e., from the middle of 2014 to 2016). As the ability of meaningmaking and critical thinking among students matured, we carried out a deeper investigation on factors pertaining to learning outcomes. During this stage of study, the progression of agency among students across different learning spaces has been analysed using the sociocultural ecological model (SCEM) for mobile learning (Cook, Pachler, \& Bachmair, 2011; Pachler, Bachmair, Cook, \& Kress, 2010). The SCEM explains the interrelationships between enablers (technology, curriculum), actors (student's ability to act) and cultural practices (social interactions in everyday life enabled by technology). This framework underpins our case study analysis to inform on the relationships between different aspects of the BYOD initiative.

\section{Digital Divides in the Learning}

The unprecedented developments in digital technologies generally referred as the 'digital revolution' created the opportunity for better access to information and services for everyone, and changed our view of society, business, and education. Generally, access to and use of digital technologies has many benefits to offer. However, in the years after the digital revolution, the pattern of the distribution of ICTs still raises concern, since not everyone has proper access to them or has adequate skills for making meaningful use of them. Many individuals, groups, and societies are still excluded digitally, from the rest of the population, causing digital division between them.

The 'digital divide' is a term that broadly represents just about any aspect of our daily life and the phenomenon has been researched and defined in many contexts. It first emerged from academic research to signify the gap between people or society who have access to digital technology and those who do not (Cullen, 2001; Van Dijk \& Hacker, 2003). However, the common understanding behind most of the research is that the digital divide is a complex issue and it is hard to understand the phenomenon within a single context and with a single definition. Careful examination of the literature gives no clear evidence of the origin of the term 'digital divide' and its meaning is still unclear. The digital divide phenomenon has been described by many authors as the most pressing social, economic, and educational issue of the information age and is now receiving increased attention from researchers and policymakers around the world (Dewan, Ganley, \& Kraemer, 2005). The education sector has been an important area of inquiry for many digital divide researchers, as they strive to inform government initiatives on strategies to address issues prevalent here. When information and communication technologies (ICTs) are introduced into learning environments, they can give rise to innovative curricula changes, inform on novel learning activities and assessment methods, and provide valuable knowledge resources to enhance learners' academic and social development (Demiraslan \& Usluel, 2008). Consequently, a number of research studies have emphasised the integration of digital technologies into existing pedagogies to transform 
teaching and learning (Anderson, 2009; Prestridge, 2007). However, questions still remain unanswered on the issues of digital divides with the embedding of ICTs into learning environments.

The phenomenon of the digital divide is complex due to the variety of economic, demographic, individual and social variables associated with it. Therefore, we have followed the grounded theory as a method for reviewing the literature in the research area as identified by the Wolfswinkel, Furtmueller, and Wilderom (2013) in three stages.

Stage one defined the scope of the review, search terms and criteria to be considered while scoping the literature review. We have chosen all of the major databases (like Scopus, Science Direct, and Web of Science, EBSCO) to access journal and conference article for our source material. Due to the nature of the issue we were investigating, we have also searched for relevant government articles and reports to reflect on the current practices. Following table below details the search terms used in the database searches.

\begin{tabular}{|l|l|l|}
\hline \multicolumn{1}{|c|}{ Concept } & \multicolumn{1}{c|}{ Search Terms } & \multicolumn{1}{c|}{ Justification } \\
\hline Digital Divide & $\begin{array}{l}\text { digital divide OR digital access divide } \\
\text { OR levels of digital divide OR nature of } \\
\text { digital divide }\end{array}$ & $\begin{array}{l}\text { To cover the width and depth of the } \\
\text { literature on the digital divide } \\
\text { phenomenon }\end{array}$ \\
\hline Education & $\begin{array}{l}\text { digital divide in education OR digital } \\
\text { divide in teaching and learning OR } \\
\text { digital divide in learning OR digital } \\
\text { divide in school }\end{array}$ & $\begin{array}{l}\text { Capturing the literature on the digital } \\
\text { divide in education }\end{array}$ \\
\hline BYOD & $\begin{array}{l}\text { technology enhanced learning OR } \\
\text { technology-mediated learning OR } \\
\text { technology mediated learning OR } \\
\text { BYOD }\end{array}$ & $\begin{array}{l}\text { Find the literature on any form of } \\
\text { integration of technology in education. }\end{array}$ \\
\hline
\end{tabular}

Table 1: Criteria for the search of relevant literature

Stage two involved combination of search terms with the inclusion criteria and querying on the relevant article databases.

Stage three involved the task of filtering articles relevant to our study. That included removing any duplicate articles retrieved from across the databases, reading abstracts to find the suitability of the article for inclusion in the review. A backward and then forward analysis was performed to establish the quality of the article. This process resulted in a final set of 29 articles for inclusion. The final list of articles that are reviewed is representative of the existing body of knowledge on the issue of digital divide in the teaching and learning in the context of integration of technology in education.

Themes emerging from the review and analysis of the literature have been grouped into the following subsections and analysed accordingly.

\subsection{Access to digital technologies}

The issue of digital access is the oldest and most widely researched aspect of the digital divide, is characterised at both the individual and the social level, and has always been the easiest determinant for defining digital divides in any of these contexts. In fact, one of the earliest understanding of the digital divide phenomenon was entirely based on the level of access to digital technologies in everyday life. According to Van Dijk (2005), Zhong (2011), and Cullen (2001) the digital access divide is the divide between those who have access to ICTs and those who do not. A large number of studies have been conducted to explore this issue of access and the impact it is causing to individuals and the society in general. When we try to identify the most important background characteristics of the digital access divide; it appears that highly correlated variables of income, socioeconomic status, educational level, occupation, and gender are the main determinants (A. Martin \& Rader, 2002; Parker, 2001; Parycek, Sachs, \& Schossböck, 2011; Van Dijk, 2006). This is an indication that individuals and societies with 
lower financial status and educational level may have poor or no access to ICTs putting them into the wrong side of the digital divide. The digital access divide is also known as the first level digital divide.

Recent trends in formal education emphasise the integration of digital learning media into existing pedagogies to transform teaching and learning (Anderson, 2009; Prestridge, 2007). Introducing ICT provides potentially valuable resources for learners' academic and social development, and introduces more visual stimulants in the learning environment (Demiraslan \& Usluel, 2008; Mardis \& Everhart, 2013). However, to realise that outcome, it is essential that every learner in the class or school be equipped with personal digital learning devices as a starting point, to enable learners to participate in technology enabled teaching and learning activities. Financial sources for that are usually the parents in most cases, and we have discussed earlier that it appears from a previous study that income is a vital factor when it comes to ensuring the appropriate digital access. The world today is suffering from various economic crises, and in the current situation, not every parent will be able to afford expensive digital devices for their children. This can put both the parent and children in a disadvantaged situation with two consequences. One, the learners or children probably will go to school without the digital device, and that would make them feel less involved compared to their peers who have these devices, leading to a poorer learning experience and isolation within the learning process. Second, the parents can feel embarrassed for not being able to afford any form of digital devices for their children, while other parents in the same school have been able to afford. This situation again has potential to lead to the feeling of disparity in society leading to a social gap.

As a result, some initiatives have been taken by communities and governments around the world to tackle this issue of growing gap of digital access. One of such initiative is digital opportunities pilot project in New Zealand discussed in earlier section, which aimed to bridge the gap of access to digital technologies to the students and teachers as a part of the educational initiative. Despite the opportunities offered to overcome digital access within the formal educational setting, evaluation of the projects later indicate that any technological intervention does not guarantee the solution of the issue of digital access divide; since this is much more deeper and involves a whole spectrum of contextual factors that exist in society.

\subsection{Digital /information literacy}

The knowledge gap hypothesis theory by Donohue, Tichenor, and Olien (1975) suggests that each new medium or technology increases the gap between the information rich and information poor. The differences in access to the medium, technology and control over its use in turn affects the abilities and skills of the users (Gaziano, 2010). With the infusion of new media or technologies into our multi-segmented social system, the segments of population having higher socioeconomic status tend to acquire this technology at a faster rate than the lower status segments (Yoori \& Se-Hoon, 2009). As a result, the gap in knowledge between these segments increases further.

An earlier study on digital divide found that merely offering individuals access to technology is not sufficient to ensure that they can use the medium appropriately to meet their needs or be on the right side of the digital divide. While equitable material access to technology can be a necessary first step to address the phenomenon of the digital divide, it is not sufficient to overcome the issue (Hargittai, 2002b). It is equally important to have proper digital/information literacy skills to use the available technologies appropriately and meaningfully (Cole, 2001; Ghobadi \& Ghobadi, 2015; Yoori \& Se-Hoon, 2009); otherwise, individuals may not be able to take even basic advantage of the technology and resources available to them. After different perspective on the interpretation of digital divide to include the digital capability as one of the aspect (Hargittai, 2002a, 2002b); several other authors have also discussed the digital media literacy (Warschauer, 2003) and digital skills (Van Dijk, 2006) in relation to the digital divide phenomenon. This new interpretations of the digital divide phenomenon has been collectively termed as the second level or second order digital divide. 
The concept of the second level digital divide is very much relevant in the context of education. First, because this is already proven that the issue of access is a reality in the current educational landscape and with the help of the knowledge gap hypothesis, we can assume that the gap in the digital and information literacy might follow soon after. Secondly, as mentioned in the earlier section, recent trends in formal education emphasise the integration of digital learning technologies into existing pedagogies. There is nothing wrong with this trend, but at the same time, it is vital that it be done in a right way. Digital opportunities project referred earlier in the section concluded that the initiative could even accentuate the existing digital divide. The reason for coming to that conclusion from the analysis of the digital opportunities pilot projects is that these initiatives are focused on treating the symptoms of the digital divide phenomenon, not the cause. During the planning and implementation of the digital opportunities projects, the meaning of equity was understood only as a matter of material access and digital skills. Instead, the initiatives around the digital teaching and learning should focus on various ways to create opportunities for learners to gain sufficient digital and information literacy skills to enable their participation in learning activities in technologymediated pedagogical context.

To realize this, a more learner-centred culture is essential where education agencies and organisations focus on enriching the ability of the learners rather than the technology/medium itself. Moreover, it can be done through the combined focus on improved connectivity (or, access to ICT infrastructure for education), content (such as digital content extracted from a variety of sources), and with confidence and capability (or use of skills for converting information into knowledge) (Ministry of Education, 2006).

\subsection{Learner self-efficacy}

Findings from prior literature on the digital divide phenomenon and outcomes from digital opportunity pilot projects show that equitable material access to digital learning technologies at home and school and having appropriate digital skills are necessary first steps, however, this alone is not sufficient for achieving digital inclusion for every learner.

When it comes to the digital access divide, main predicators include the personal attributes like gender, educational level, and social attributes like affordability and socio-economic status. Lack of adequate access to digital technologies then limits the individual's digital/information literacy levels. This can further affect the learning activities of learners, restricting their ability to meet the learning objectives (Ersanl,, 2015; Wei et al., 2011; Yusuf, 2011). When the digital access divide leads to the divide in terms of their learning capabilities, this can soon start influencing various facets of the social cognitive abilities related to the individual's learning, usually referred as the self-efficacy of the individual/learner. This selfefficacy among learners is very important to translate the opportunities offered by the technology-mediated teaching and learning practices. Eventually, the limited self-efficacy levels among learners can potentially cause a life-long impact on the individual's learning tendencies and abilities which can restrict them in acquiring new skills and knowledge in using the available technologies thereby reducing their opportunities (Garipagaoglu, 2013). Therefore, there is a need to extend the digital divide research in the context of technologymediated pedagogical practices, towards additional fields of enquiry beyond just access and skills.

\subsection{Nature of the technology usage by learners}

In the context of the technology-mediated pedagogical practices, broader definition of equity reaches beyond level of physical access to technologies and skills to make use of those technologies. Having adequate access and individual's ability to utilise the available technologies are necessary first steps towards consuming information. To achieve wider digital inclusion in the context of technology-mediated pedagogical practices, engagement has to move beyond consumption to participation and creation. Faced with rich variety of digital tools, learners can engage with digital media and exchange information with each other, for example via posting messages to chat rooms, newsgroup and forums, or use peer-to-peer file 
sharing sites all of which can lead to building up of social capital (Brake, 2014) and achieving better learning outcomes. However, some communication tools can often be used for pursuing entertainment and leisure activities such as downloading music, streaming videos, surfing for fun, playing online games and cheering up each other to pass time (Van Deursen \& Van Dijk, 2014). However, such forms of entertainment and leisure motives can interfere with classroom teaching and learning activities. Hence, behavioural aspects of the individual learner are equally important to realise the equity in terms of the learning outcomes among learners. The way individual learners make use of the available technologies can have a huge impact on student achievement, as the usage of digital technologies can be done meaningfully or not (Jones \& Issroff, 2007; Wei et al., 2011). In addition to that, since the learners will be having access to all kinds of games and other resources in the internet at their fingertips, the classroom might experience disruptive behaviour from the students (Bru, 2006). This remains one of the challenges for teachers to keep the learners on task and guiding them to make meaningful usage of available technologies during the learning activities. Therefore, the nature of technology usage by learners is a very important aspect when investigating the issue of the digital divide, as the nature of the technology usage determines the productivity of the learning activities.

\subsection{Motivation/belief}

Introduction of the technology-mediated teaching and learning requires a big shift in the way teachers teach in classrooms and how students engage in learning activities. Redefinitions of the learning activities and changes in the expectation levels means that students often have to come out of their comfort zone and embrace the new way of learning. Some might appreciate it and others not. Therefore, the shift in the way of learning in the technology-mediated learning environment requires a careful transition through which the learners can be kept motivated.

Constructivist learning theory by Jean Piaget holds that learners learn more effectively through the active design and development of projects meaningful to them and the community around them (Vogel-Walcutt, Gebrim, Bowers, Carper, \& Nicholson, 2011). Through this process of learning, they actively construct new knowledge and become more deeply involved in their learning process. When learners are novices, they need to be guided and supported to construct knowledge and then integrate knowledge to create further knowledge. However, without proper instructional guidance to inform learners on how to add to existing knowledge in their learning process, their belief in themselves could waiver and thereby affect their motivation to learn. For that reason, it is a very important area to investigate and to find how motivational issues can affect the learning outcomes of the learners.

\section{Analysis and contextualisation of literature into study}

The world around us is transforming and changing every day, and therefore understanding the phenomenon of digital divide only from the notion of material access (haves and have nots) and adequate digital/information literacy skill (can and cannot) may not be sufficient. Apart from those aspects, studies on how individuals engage with and make use of the available technologies, as an expressive tool, in and across different contexts to achieve set goals are very important (Brandtzæg, Heim, \& Karahasanović, 2011; Brosnan, 1998). As explained in the three level digital divide by Wei et al. (2011), the literature shows a clear shift in digital divide research around acceptance and adaptation of digital technologies, the nature of technology use, changes in attitude and behaviour, ability of meaning making, skill development, and knowledge acquisition in recent years. It has been collectively termed as the digital outcome divide or third level divide and is a more recent analysis of the digital divide phenomenon (Brandtzæg et al., 2011; Gunkel, 2003; Lenhart et al., 2003; Partridge, 2003; Wei et al., 2011; Zhong, 2011). 


\begin{tabular}{|c|c|c|c|}
\hline & \multicolumn{3}{|c|}{ IT Adoption Stages } \\
\hline Individual & Digital & Digital & Digital \\
\hline Organizational & & Capability & Outcome \\
\hline Global & Divide & Divide & Divide \\
\hline
\end{tabular}

Figure 1: Three level digital divide framework (Wei et al., 2011)

The Figure 1 depicts the adoption of information technologies across three stages, having access to ICTs (digital access divide), developing usage capability (digital capability divide) and achieving outcomes (digital outcome divide) (Wei et al., 2011). The importance of computing environments is growing and so is the penetration of digital tools and technologies within every aspect of our daily lives. With the ever increasing adoption of digital technologies in educational activities, it is important to find how that affects the ability to use and the level of outcomes gained through the adequate appropriation of the technologies. There is also an area to understand in this context that, if the digital access divide in anyway contributes to the following levels of the digital divides. This extends the area of enquiry to investigate the effects of the digital access divide on the subsequent two levels of divides.

It is therefore evident that, there are still some unanswered questions around, if one level of divide leads to another in the context of technology-mediated teaching and learning process? It is especially unclear how digital access divide will affect the digital capabilities divide and the learning outcomes in turn. Therefore, there is a need to extend the digital divide research towards additional fields of enquiry beyond just access and digital skills to understand the evolution of the digital divide phenomenon within the context of technology-mediated teaching and learning environments. Specifically, with the increased penetration of digital technologies into the teaching methodologies and learning activities by the BYOD classroom initiative, the three level digital divide framework by Wei et al. (2011) guides the study on how the existing and new digital divides will evolve within the BYOD classrooms.

For that reason, we have adopted the three level digital divide framework and applied it to the context of our study. While adapting the framework for our study, we mapped the three levels of IT adoption stages to the three levels of digital divides in the learning process. Specifically, ICT adoption stages includes access, capability and outcome divide stages, which matches with the digital access divide, digital capability divide and digital/learning outcome divide.

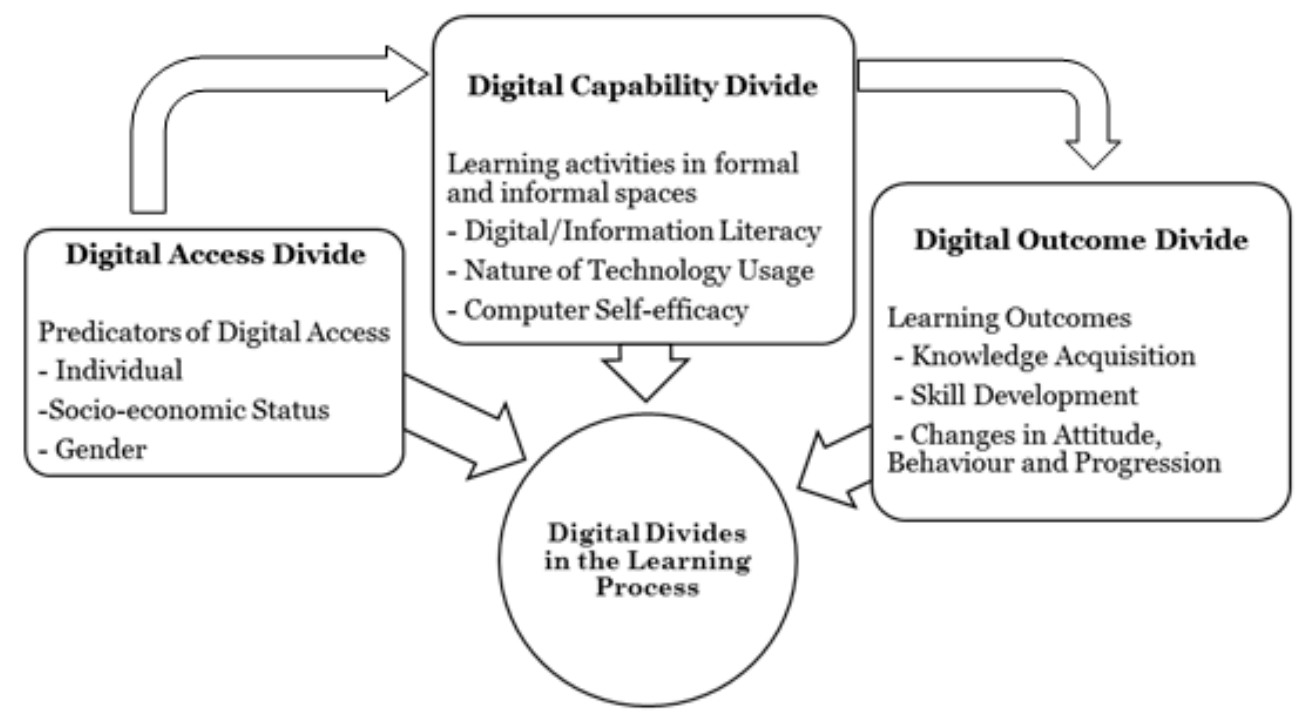

Figure 2: Three levels of the digital divide in learning applied to the context of our study. 
As illustrated in Figure 2 above, the main predicators for the digital access divide are individual (like educational level), socio-economic (like affordability) and gender, which has potential to contribute to the digital divide in learning directly or indirectly through its effect to the digital capability divide. Further to that, the digital capability divide is influenced by various factors during the learning process as the technology-mediated learning activities can occur in formal or informal learning spaces, since contemporary learning technologies offer learners the ability to extend their learning beyond the formal learning spaces and continue their learning in informal spaces (Murphy, Farley, Lane, Hafeez-Baig, \& Carter, 2014). In this context, the formal learning space constitutes classrooms and informal space constitutes anywhere outside of the school/classroom. Specifically, the factors determining the digital capability divide are digital/information literacy of learners in performing different types of computing tasks, nature of technology usage by learners (motivation to learn), and computer self-efficacy measurements of their capabilities. We can consider these factors as the focal constructs for this study through which personal, behavioural and environmental factors further influence the knowledge acquisition, skill development, and progress in attitude and behavioural aspects in learner, resulting in digital outcome divide. As shown in the framework in Figure 2, the nature of digital divide may change from one form to another over the different stages of technology adoption. Therefore, to examine digital outcome divide, various factors in first two levels has to be investigated to find their effect on the extent of knowledge acquisition, skills development and changes in attitudes, behaviours, and progression in learning.

\section{Case Narrative and Research Questions}

In 2011, a New Zealand school decided to integrate digital learning technologies into everyday teaching and learning activities in the form of one-to-one portable digital devices for all students in a cohort. The school informed all parents and students that they were expected to bring a one-to-one digital learning device (preferably an iPad2) into the classroom in year 9 (students aged 13-14) for the 2012 academic year. The most controversial and unique aspect, which makes this initiative different from most others, is that the parents were told they must cover the full cost of the required digital learning devices for their children, whereas similar projects in the past (like the Digital Opportunities projects) had provided devices and resources through the schools. The school's decision resulted in a high profile news story in the New Zealand Herald, a national newspaper, triggered by a complaint from a parent about being asked to buy a digital device for their child. This set off a significant public and media response, leading to news stories on TV, radio, and online debates on various news sites and forums.

Drawing on from the initial evaluation of the literature review on the research topic and the preliminary analysis, the purpose of this research study is (a) to investigate whether and, if so, how, the introduction of BYOD initiative has changed digital divides and affected teaching and learning process, in both formal and informal learning spaces; (b) and, to evaluate the effectiveness of BYOD initiative on students' learning outcomes. Therefore, the main research question posed in this paper is:

\section{How have the digital divides in teaching and learning changed over the years of BYOD classrooms?}

The following subsidiary questions influence the above research question:

1. How has the digital access divide evolved because of the BYOD classrooms?

2. How have the digital capabilities divide evolved because of the BYOD classrooms?

3. How have the learning outcomes (knowledge acquisition, skills development, and progression of attitudes and motivation) evolved because of the BYOD classroom? 


\section{Socio-cultural ecological model to analyse the BYOD classrooms}

The focal constructs identified in the three level digital divide framework applied in the context of our study (in Figure 2) has potential to disrupt learning activities not only on formal spaces like classrooms but also in informal spaces, such as home/out of school. Therefore, the study will need an analytical lens that helps to capture learning process within formal and informal learning spaces mediated by one-to-one digital learning devices. Our analysis framework (Figure 3 below) adapted from socio-cultural ecological model by Pachler, Bachmair, et al. (2010) has been used to analyse the interrelationships between three components, namely structures, agency and cultural practices, within formal and informal learning spaces mediated by one-to-one ICTs. The idea behind this framework is that teaching and learning practices using one-to-one devices in and around different learning spaces is influenced by a triangular relationship between structures (imposed by curricula, communication, technology), agency (such as self and other users/actors) and cultural practices (or social interactions in everyday life) (Pachler, Bachmair, et al., 2010; Pachler, Cook, \& Bachmair, 2010).

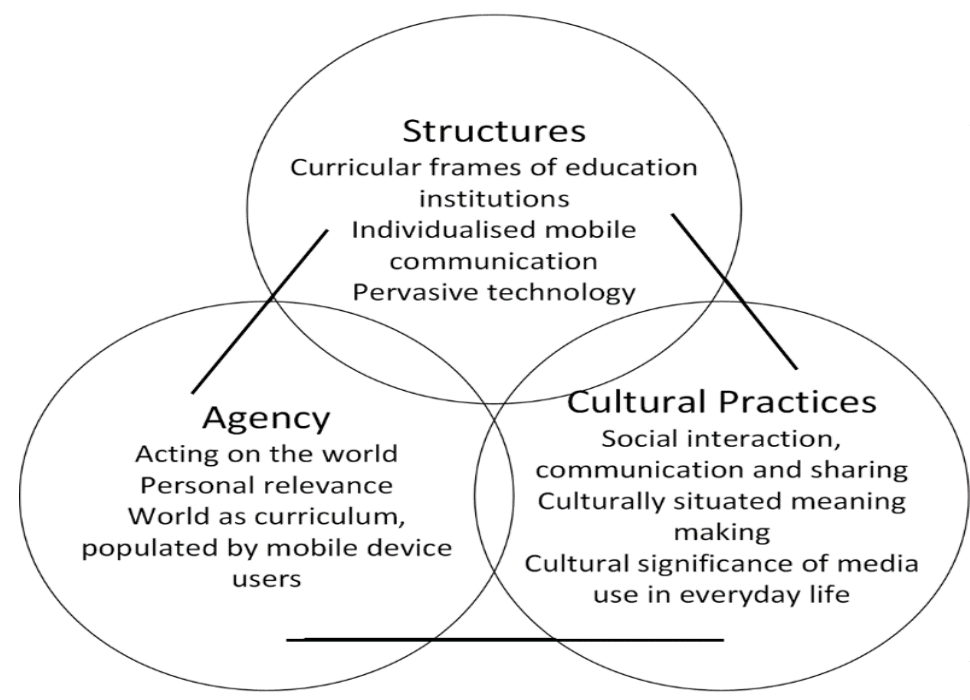

Figure 3: The sociocultural framework used in our analysis (adapted from Pachler et al, 2010)

Each of the three components of the socio-cultural framework actually relates to the BYOD case study we are investigating and helps to scaffold the interrelationships between key stakeholders, practices, and structures governing the teaching and learning. For that reason, the sociocultural ecological framework for mobile learning by Pachler, Bachmair, et al. (2010) have been adapted for this study, as this provides much needed analytical lens for the analysis of data. We have further extended the socio-cultural ecological model to explain the interrelationships in a technology-mediated teaching and learning environment. Figure 3 shows the various points of references within each components and helps to scaffold the interrelationship between key stakeholders, practices and structures that relates to the BYOD case study under investigation.

One of the components, the agency, is all about the ability of actions made by individuals within their worlds. It includes the capacity to construct one's own learning responsibly and to build information literacy skills and self-efficacy around media use. In the context of our study, the agency is having adequate digital/information literacy skills for using digital tools, thinking critically to process the information and personalizing that information knowledgeably. In this manner, a habitus of learning emerges from individualized expertise which can then be applied to formal learning practice (Pachler, Bachmair, et al., 2010). Cultural practices on the other side emphasize the areas that can benefit learning, as they relate to collaboration, social interaction, meaning making and media use. Cultural practices in the context of BYOD is 
enabled by a digital communications medium and is transforming how individuals interact and use media in everyday life. Episodes from everyday life can be captured and shared to create cultural artefacts. Once captured and in tangible form, they provide a context and can then be used for further discussion, reflection and analysis. At the end, structures relate to immersion in digital learning technologies, prevalent school infrastructure to facilitate BYOD classrooms, and the curriculum within which they are applied. For example, the educational experience is structured around projects, assignments, and presentations where the media can be used to generate and express relevant content for assessment purposes.

\section{Research Methodology}

A number of approaches can be used to investigate the integration of digital learning technologies and strategies in classrooms. Some of the approaches include social constructivist perspective (Khalid, Jurisic, Kristensen, \& Ørngreen, 2014) and experimental approach using pre- and post- tests (F. Martin \& Ertzberger, 2013). Cheung and Hew (2009) suggest research designs to include surveys, interviews or observations, especially when investigating technology-mediated teaching and learning, and similar initiatives.

The case study method is appropriate when the objective is to learn about some environment in more detail (Dubé \& Paré, 2003). A case study explores a phenomenon in its natural environment by using multiple data collection methods to gather information from variety of sources associated with the phenomenon under study (Baxter \& Jack, 2008). The boundaries of the phenomenon are not apparent at the initial stages of the research, and no intervention or manipulation tactic is to be used (Benbasat, Goldstein, \& Mead, 1987; Dubé \& Paré, 2003; Yin, 2003). Case studies are common research designs for exploratory (theory building), explanatory (theory testing) and descriptive (description of the context) in social science research (Yin, 2003). In this study, a descriptive case study design has been used to present a longitudinal case of a secondary school implementing technology-mediated pedagogical practices in the form of the BYOD classrooms. The case we have selected for conducting the study is co-educational secondary school, which is state funded and is ranked at the decile $9^{2}$ in the New Zealand school ranking system based on the socio-economic status of the area surrounding the school.

According to Yin (2003), case study research design with a single case is suitable when the study represents a unique, revelatory or critical case. The case chosen is unique, revelatory and representative of the research problem and field of enquiry being investigated, since the said case is one of the earliest adopters of BYOD classroom or similar initiative in New Zealand. This study follows an in-depth single case study research design with the continued investigation over a period of five years.

\section{Research instruments and timeline of data collection}

Research instruments such as surveys, interviews, and observations have been used to collect data from students, teachers and parents. A low-risk notification has been obtained to conduct the study from the university human ethics committee well before starting the data collection. Parents were informed of the research being conducted through school newsletter, and permission was sought for students below the age of 16 years. All of the research participants were given a written description of the purpose of the research study, along with the list of the University officials to be contacted if the participants feel the ethical consideration is not adhered. Participant provided either consent through online consent form (for an online survey) or signing the paper consent form (for interviews) before researcher started recording data. Data have been gathered using different methods at various rounds as outlined in the following table.

\footnotetext{
${ }^{2}$ Deciles are a measure of the socio-economic position of a school's student community relative to other schools throughout the country.
} 


\begin{tabular}{|c|c|c|}
\hline Stages & Data collection timeline & Data collection methods \\
\hline Stage 1: Baseline & Early-2012 to mid-2012 & $\begin{array}{l}\text { Open-ended surveys with students, } \\
\text { teachers, and parents } \\
\text { Classroom observations in targeted } \\
\text { subject areas }\end{array}$ \\
\hline Stage 2: Follow-ups & Mid-2012 to mid-2014 & $\begin{array}{ll}\text { - Semi-structured interviews with a } \\
\text { randomly selected sample of students, } \\
\text { teachers, and parents } \\
\text { - Two rounds of open-ended follow-up } \\
\text { surveys with students, teachers, and } \\
\text { parents } \\
\text { - Classroom observations in targeted } \\
\text { subject areas }\end{array}$ \\
\hline Stage 3: Summative & Mid-2014 to late-2016 & $\begin{array}{l}\text { Two rounds of semi-structured } \\
\text { interviews with teachers }\end{array}$ \\
\hline
\end{tabular}

Table 2: Stages of data collection

During the first stage of the study, the answers to the first research question related to the digital access divide (i.e. how has the digital access divide evolved because of the BYOD classrooms?) have been investigated. Initially, themes that emerged from the public debate surrounding the BYOD classroom initiative raised some concerns towards the potentially digitally divided classroom. In a bid to find answers to concerns raised, our initial investigation focused on affordability and availability issues of one-to-one digital learning devices among the students. Results from this stage of investigation then informed the nature of subsequent research questions to be posed for the remainder of the study.

At the stage 2, the research activities were focused mostly on finding the answer to the second research question about digital capability divide (i.e. How have the digital capabilities divide evolved because of the BYOD classrooms?). This stage of analysis briefly revisits the access and competencies divide issue discussed in the earlier stage, and touches on how digital capability might influence the next level of digital divides in learning (i.e. learning outcomes divide) before investigating that in detail at the third stage. The previous stage of study along with the review of the literature helped us to identify a number of factors that have potential to influence digital capability. We analysed data from students, teachers, and parents to learn how certain factors influenced the capability of an individual learner.

At the stage 3, the research activities were focused mostly on finding the answer to the third research question about digital capability divide, that is, How have the learning outcomes (knowledge acquisition, skills development, and progression of attitudes and motivation) evolved because of the BYOD classroom? We combined findings from the first two stages of research to investigate how digital outcome divide evolved during the last 5-year implementation of BYOD classrooms initiative. During this stage of investigation, we conducted further semi-structured interviews with teachers who had participated over the whole BYOD initiative period. This helped to gain more insights on changes in learners' attitudes and self-efficacy over the five-year long journey with the BYOD policy.

\section{Data analysis and findings from the study}

The data to analyse the research questions came pre-dominantly from the surveys and semistructured interviews conducted with the students, teachers, and parents over the past 5 years. Qualitative data provided personal narratives involving classroom interactions with technology, thereby revealing rich insights during the different implementation phases of the BYOD policy. Interviews and text response data from surveys have been coded and categorized 
under three research questions to be analysed. Thematic analysis was then performed on each of the category resulted from the qualitative coding using NVivo, a qualitative data analysis software.

This is evident from the findings of this study that, factors pertaining to one level of divide can also affect and contribute to the divide in the subsequent level. For example, limited or no affordability and ability to operate digital technologies along with the social and environmental conditions of homes and schools (digital access divide), further influences affordances in various sources of social cognitive abilities related to individual's learning activities and computer self-efficacy levels, demonstrating digital capability divide among individuals (Wei et al., 2011). These both levels of divide (digital access divide and digital capability divide) will, in turn, affect how new skills and knowledge are honed; having further implications on the individuals' learning outcomes leading to digital outcome divide.

This section discusses the study findings based on the three levels of digital divide framework in learning adapted from Wei et al. (2011). The sociocultural ecological model (SCEM) for mobile learning by Pachler, Bachmair, et al. (2010), has been used as the analytical lens to answer the three subsidiary research questions.

\subsection{How has the digital access divide evolved because of the BYOD classrooms?}

Initial results coming out of the analysis based on the baseline data indicated no presence of digital access divide of any nature within the BYOD classrooms. Despite survey data indicating $100 \%$ access, few students turned-up at school without any kind of one-to-one device. The school tried to resolve this issue of potential gap in device ownership by providing notebook computers to those who did not have any learning devices to use during school time only. However, these students could not take those devices to home.

Further enquiry of the issue at the subsequent stage of the investigation revealed more details about access issue among students in terms of the varying level of access to digital learning tools and technologies. While majority of the students had access to the one-to-one digital learning devices and internet at school and home to support their learning, others in the classroom had limited levels of access (including no internet access at home, poor internet connection at home, computers at home but no one-to-one devices to use in classrooms) thereby restricting their opportunities.

Therefore, despite the school's efforts to bridge the gap of access by facilitating learning devices during school hours, a significant number of students were missing the opportunities offered by the full access to digital learning tools and technologies. This finding was in contrast with the fact that the school area is ranked decile nine (representing a region where citizens belong to a relatively higher socioeconomic status). One student stated in the survey:

"I usually do not spend much time with the tablet at home because I don't have the internet at home. Sometimes I can't complete my work at home because of the internet".

Similarly, another student too had responded:

"Well in my house we don't have dial-up so I only use my tablet for the project I have downloaded. I don't have the internet at home."

Teachers also confirm the issue of internet access at home:

"Something that is a problem is internet access at home or broadband access. Because children are saying honestly that, 'I cannot do this at home'. I have one bright student in my class who said she doesn't have the internet in her home or the device either".

Many of the parents also expressed their concerns about not being able to make the recommended device available to the students. Some of them said: 
"One-to-one devices are great for education but there needs to be equity for families that cannot afford devices".

Another issue that came up related to digital access was the compatibility issues between different types of one-to-one devices within the classroom learning. Interview responses from student indicated that some students have been unable to carry out their usual learning activities during classroom because of device compatibility issues. Responses from teachers confirmed that most of the learning activities are designed keeping iPads in mind, and these activities may be difficult to perform using a laptop and android devices. Regarding compatibility issue, one student says:

\section{"I felt disadvantaged sometimes because I have a laptop and all the teachers talk} about is apps for iPads".

However, students and teachers were prompt in finding alternative ways for continuing participation in learning activities for those affected in these situations. Also, the overall survey responses do not reflect incompatibility issues to be prevalent on a larger scale in everyday learning, making this a relatively non-significant issue for the further investigation.

Despite some degree of access, compatibility and technology issues being discovered, BYOD initiative had certainly provided a greater degree of access to digital learning technologies to learners. In addition, the access to the internet at homes has improved in the subsequent years, which contributed to narrowing down of the gap in access to digital technologies and resources for students, marking a gradual improvement. Looking into the positive change in terms of access/reach, BYOD initiative can be considered therefore an enabler in this context.

\subsection{How have the digital capabilities divide evolved because of the BYOD classrooms?}

The baseline and follow-up survey data between 2012 and mid-2014 helped in laying the foundation of the study and framing aspects of digital divide issues as they evolved in the BYOD classrooms. As the pedagogical practices, including teaching methodologies and learning activities progressed, so did, the different nature of digital divides in learning which started to appear in the second set of the survey responses. The teaching and learning practices during this period seemed to concentrate more on critical thinking and analysis of available information rather than consuming as it is. Many students found BYOD classroom much more relevant and useful because of those changes.

Because of this shift in teaching and learning practices/activities from consumption to analysing critically before applying it into their learning, the area of investigation shifted from just digital skills to much broader area of skills (i.e. information literacy and computer selfefficacy). Survey and interview data from this phase suggest that a significant proportion of students lack critical analysis of information to apply to their learning activities. Information literacy and computer-self efficacy skills are critical to lift the student's ability around the meaningful usage of technology and critical thinking and analysis, which affects the acquisition of knowledge in students. Therefore, it is necessary that information literacy and computer self-efficacy are considered as the key factor into the investigation of the digital capability divide and also the evolving nature of digital divides in learning, since that can either help or risk the learning outcomes, determining the digital outcomes divide.

The investigation into this phase also looked into the motivational and behavioural aspects related to the students, potentially affecting their digital capability. When asked what have been their major challenges, $17 \%$ of teachers indicated classroom management in the BYOD context. This was mainly because of the extra effort teachers had to put in their classroom to prevent students going off task. A number of measures have been taken to caution students, but this had little or no effect. Therefore, the issue remains one of the challenges for the teachers. Parents in their responses, also clearly voiced their concerns regarding the unsupervised usage of devices by their child. A number of parents worried about the 
unsupervised nature of their child's device usage and the potential harm it may cause. One parent worried for change in their children's behaviour and social interactions say:

"Yes I constantly have to take the device off my child she seems to be constantly on it and it is a constant battle, she has lost interest in a lot of other activities".

The unsupervised access of device and the internet by students could also be a concern because of the widening digital skills gap between the students and parents. While students are exposed to the different forms of digital technologies as an integral part of their learning, their parents severely lack the ability to monitor their digital activities. In a different study, Newhouse, Lane, Cooper, and Twining (2014) reported similar findings in a learning environment using web 2.0 technologies. Because of this, parents have a growing concern about the safety of their children from online content. In the latest surveys, some of the parents responded as:

"Negative impact: they spend a huge amount of time at home on their devices. It is often very difficult for us to know whether it is school related or not. As it is a condition of them attending school we are bound to allow them access to their devices."

"Yes, the definite negative impact I have seen in our community and at home. A huge amount of social bullying and inappropriate use of the device to take photos, and send images, messages to others about others etc. Children as young as Year 7 and 8 being given complete access to the internet and everything on it getting into pornography (written and visual) and chat rooms talking to older men and women."

Lately, there have been reports of students using some of the applications and sites that are used for internet bullying in New Zealand schools. There is no report of that from the school where this research is based on, but this is clearly an alarm bell for school and parents involved in the BYOD classrooms. Therefore, there is a mixed result from the analysis in this context. Therefore, while the results show improvement in the digital/information literacy, they also raise concerns caused by the digital practices/habits of the students.

On the other hand, initial skill levels of staff reported indicated towards potentially lower digital capability, which was improved in the later stage of the study. However, it should be noted that the staff were early adopters in the first year of the BYOD initiative who volunteered to take part into the BYOD classrooms initiative. This suggests that we cannot expect the digital skills of staff overall to reach its maximum potential until the BYOD policy has been fully rolled out across all school years so that all the staff has had the opportunity to fully develop their digital skills. Nonetheless, the school has also helped in that period to setup workshops to foster peer-support into adopting and integrating one-to-one digital learning device into the classroom pedagogical practices through development of their own digital capability. This was vital for the success of the BYOD classroom initiative, as this method of professional development through the community of practicing teachers in the context of technologymediated teaching and learning environment is more sustainable (Watson \& Prestridge, 2003), and teachers expressed appreciation of the ongoing peer-support they received from the community of learning. Overall, some vicissitudes in the digital/information literacy skills and behavioural and motivational concerns have been observed in the BYOD classroom initiative. Despite that, the digital capability is continuing to improve over the five-year period of the investigation. Yet, the analysis of some focal constructs like computer self-efficacy is cannot be concluded at this level and has to be analysed also in the context of the learning outcomes next.

\subsection{How have the learning outcomes (knowledge acquisition, skills development, and progression of attitudes and motivation) evolved because of the BYOD classroom?}

Certainly, addressing and bridging of access and digital/information literacy skills are important aspects in the context of the BYOD classrooms. At the same time, having reasonable access and adequate skills will not guarantee overall digital inclusion. Even with the innovative technologies and best digital/information literacy skills, students may still struggle in their 
learning activities. Therefore, our analysis extended its focus on some of the factors contributing to the learning outcomes divide.

One of the factors that closely affect the learning outcomes is knowledge acquisition. In the recent years since the introduction of BYOD classrooms, a shift in the teaching and learning practices and activities has been seen. The learning activities are now designed in such a way that it requires students to gather information, synthesize it and analyse critically before applying into their learning. Many students have appreciated the way they are currently learning. Whereas earlier a small proportion of students expressed concerns regarding not being able to meet that standard. However, recent interviews with teachers indicated that there is huge progress among students in critical thinking abilities, such as gathering, analysing and applying information into their learning.

"The results that we are getting since having BYOD are improved. I definitely would be very surprised if results go down."

Another factor that affects the learning outcomes is the attitude, behaviour, and motivation. Apart from few exceptions, majority of learners find BYOD classrooms a great idea. Interestingly, despite the potential opportunities offered by the BYOD classroom, some students earlier expressed some apprehensions with the initiative. However, the latest data from the teacher interviews shows a very different picture on the issue indicating positive changes in attitude, behaviour and motivation.

"There far more engagement and there is far more openness with their work. I remember years ago students sort of covering their work and not showing it to teachers when they were writing, if their handwriting was bad or spelling was bad. Whereas now the kids are lining up to show their work, whether it's the video, report or presentation."

Learner self-efficacy is another factor that can affect the learning outcomes. It has its root in the three level digital divide framework (Figure 2), adapted for our research. The framework describes self-efficacy as one of the major predicators of the digital capability divide, which in turn leads to digital outcome divide in combination with some other factors. Recently, a number of teaching and learning strategies implemented have been designed to promote selflearning and maximize student engagement. All of that have been done with emphasis on student led learning which does not just maximize student engagement, but also gives them more freedom, responsibility and ownership of their learning. The following comments from different teachers show the change in students' attitude in the new environment.

"On a good day, you come here and you will see students outside. They are still on task but they are choosing different learning environment for them."

"Very first thing is, let the students be and trust that they are going to take ownership of their learning."

As a result, the changes that are appearing now indicate that students are developing into independent learners. One comment states it simply:

"For majority of students, they have improved on critical thinking ability."

At the same time, concerns about every student not being on the same page and not having same level of information literacy skills were also raised.

"Some students are lot more confident in finding, processing and applying information they come across and others don't. I think that's what separates your achieved students with excellent ones, because quite often your excellent students have higher level of information literacy."

Interestingly there were no conflicting views about improvement in student learning outcomes over the years of BYOD policy. There was a strong feeling among teachers that BYOD has definitely contributed in improving learning outcomes. 
"The results that we are getting since having BYOD are improved. I definitely would be very surprised if results go down."

"I think the critical thinking ability in majority of students have improved because I find their essays lot more detailed and with in-depth information. They have lot more insightful comments."

Overall, the latest round of data has shown improvements on many aspects, including school curricular practices, giving students' agency and ability of meaning making all of which contribute to build students self-efficacy in the context of BYOD policy. This in turn has a positive effect in achieving better learning outcomes among students.

\section{Contributions}

This study reports on a longitudinal investigation of a technology-mediated teaching and learning initiative, in the form of BYOD classrooms in a New Zealand secondary school. The study draws on findings from start of the BYOD initiative onto 5 years of its implementation. Using a narrative approach, the study has described how the teaching methodologies and learning activities have changed over the years, and how the existing and new digital divides in learning evolved within those changes and with increased penetration and adoption of digital learning technologies across formal and informal learning spaces. The data for the study comes from a variety of stakeholders into the BYOD classrooms initiative (including teachers, students and parents). The longitudinal inquiry at each stage of study was guided by data collected from previous stage, as the issues that evolved at previous stage became part of the subsequent inquiry. The study reported these issues as they came up, discussed their resolutions and informed on new issues, which came at the forefront over the 5-year period.

This research study has utilized two main frameworks to analyse transformations within the technology-mediated teaching and learning (BYOD classrooms) environments. The theoretical framework developed for the study (Figure 2) has been adapted from the three level digital divide by Wei et al. (2011) which helped the study to capture the continuously evolving nature of the digital divides with the advances in the technology adoption into teaching methodologies and learning activities. Also, the study uses analytical lenses of sociocultural ecological framework for mobile learning (Figure 3) by Pachler, Bachmair, et al. (2010) to allow the analysis to capture the interrelationships between the various stakeholders, the learning environments and curricular structure of the school. The key constructs identified for the study (which includes digital/information literacy, computer self-efficacy, and nature of technology usage) from the three level digital divide framework for learning (i.e. theoretical framework developed for study) have been cross-referenced with the three components of the sociocultural framework for mobile learning (agency, cultural practices and structures). The combination of these two frameworks in analysis helped to capture the learning activities situated across the formal and informal learning spaces and investigate various sources of social cognitive abilities related to individual's information literacy, learning activities and computer self-efficacy levels and its effect on the learning outcomes of the students.

Study posed a series of research questions in response to the research problem identified for the investigation. The main overarching question was aimed at the overall evolution of the digital divide in learning in the context of the technology-mediated pedagogical environments. To answer the overarching question three sub-questions aimed at the three levels - digital access divide, digital capability divide, and digital outcome divide - were posed. Therefore, the study outcomes are mapped under these three broad digital divide levels. These outcomes from the study are explained below.

\subsection{Outcomes related to digital access divide}

Despite the speculation and anticipation during the initial phase of the BYOD classrooms initiative, the findings suggested no evidence of a widening gap in terms of the digital access divide within the BYOD classrooms. To be precise, there were some reports of limited or no access to internet at homes, which eventually improved at the later stage of the study. The 
BYOD classroom also experienced some issues related to the compatibility of one-to-one devices in terms of participating into the classroom learning activities, as the majority of the resources and activities were found to be developed keeping recommended devices (i.e. iPad) in mind. This led to increased efforts by teachers to bridge the capability of the various devices.

An earlier study had cautioned that technology integration initiatives in schools might accentuate existing digital divides (Rivers \& Rivers, 2004). This study finds that such an initiative (i.e. the BYOD classroom initiative) did not trigger or widen the existing gaps/level of gaps in access to digital divides. It is specifically clear that the fear of having digitally divided school environment based on the previous notions about the integration of technologies proved to be unfounded.

\subsection{Outcomes related to digital capabilities divide}

The second stage of study started on a relatively firm base, after finding not much evidence of digital access divide within the BYOD classrooms, where various aspects of the digital capability divide were investigated using online surveys and semi-structured interviews. In addition, the continuing classroom observations data was also used to inform the analysis at this stage. A major finding from the analysis at this stage indicates that digital skills in learner do not support their ability of learning as understood earlier. Students may have an excellent level of digital skills in operating the digital learning devices, but they may not be able to take advantage of that skill without the proper information literacy skills, suggesting ability of learning in learners is guided largely by the information literacy skills in the technologymediated teaching and learning situations.

The BYOD classrooms initiative enabled teachers to be more innovative in classroom learning activities, for better student engagement. Students were offered greater flexibility and agency making them more responsible for their own learning. At this time, the difference between digital skill and information literacy skills become evident. The analysis found an increase in frustration and motivational issues among the students with no or limited information literacy and critical thinking ability. Because of this, the gap in ability to learn between students with and without the information literacy and critical thinking skills emerged. The analysis strongly indicated the presence of this gap mid-way during the five-year long research.

However, this gap become narrow at the later stage of the analysis, which suggests a possible explanation that it took some time for students to accept the teaching and learning practices in the BYOD classroom and to develop the vital information literacy skills, with the huge change in the classroom curricular structure.

\subsection{Outcomes related to digital outcomes divide}

The findings of the second stage of the research provided the informed beginning of the third stage enquiry as more understanding was gained around factors pertaining to the digital capability divide. This was important, as the factors pertaining to the digital capability divides are the focal constructs for this study (digital/information literacy, computer self-efficacy, and nature of technology usage), through which personal, behavioural and environmental factors further influence learning outcomes resulting in digital outcome divide.

From the analysis of these focal constructs, computer self-efficacy emerged as the factor with greater influence in shaping up the learning outcomes. The learner self-efficacy when combined with the other predicators of the digital capability divide, further influenced affordances in various sources of social cognitive abilities affecting individual learner's knowledge acquisition, progression, and changes in their attitude and behaviours. This leads to difficulty in learners to engage and apply technology to attain their learning requirements, and therefore puts them to the wrong side of digital outcome divide.

\section{Limitations and future research}

As a part of the five-year study of the technology-mediated teaching and learning initiative, we have been able to explain some of the unanswered questions around the issue of digital divide 
in the learning process. Rich insights have been shared in the context of technology-mediated pedagogies and specifically BYOD classroom, as to how digital divides moved beyond access and skills to ensure inclusive learning outcomes. However, the study also has some limitations as explained next.

Firstly, the choice of the case study was restricted by the availability of the suitable cases representative of the research problem at the start of the study. The case study selected for this research is one of the first schools to introduce the fully technology-mediated pedagogical practices in the form of the BYOD classrooms initiative. That has limited our options in terms of the selection of the case for the study. That led the study to use the single case of a BYOD classrooms initiative in a secondary school in New Zealand with the decile ranking of nine based on the New Zealand school ranking system. While this study is limited to a single case, it takes account of a five-year longitudinal period to reveal a comprehensive understanding about technology-mediated transformations in teaching and learning spaces.

However, a comparative study involving more than one case study including schools with varying level of decile ranking relevant to the research problem would give a better understanding of digital divide in learning across various socio-economic regions. In a recent development in the education policy, the government reform to scrap the decile ranking of schools by 2019 is currently under discussion (Parliament, 2017). The discussion is around the argument that decile ranking is a blunt tool, which measures schools with socio-economic region rather than quality of education.

Secondly, because of being the pioneer school to introduce such initiative in New Zealand there was a huge media controversy surrounding the school's decision and was covered in many of the national and local media (Mass, 2011; Moore \& Tasman-Jones, 2011; Tasman-Jones, 2012). The media spotlight and speculation surrounding the initiative could have had some impact on steps taken by staff to better manage digital exclusion. However, triangulation of data sources (i.e., classroom observation, student surveys and parent and teacher interviews) has been used in data gathering process to strengthen the study findings.

This study provides a very good understanding on the issue of digital divides in learning and captures the evolution of the existing and new digital divides in the context of the technologymediated pedagogical interventions and initiatives. While doing so, the study predominantly collects and analyses the qualitative data from the longitudinal case of a BYOD initiative, involving various stakeholders like students, teachers and parents. However, analysis of student learning outcomes based on quantitative measures like student performance data have never been included into the study. Therefore, the future directions of research on this topic lie in the inclusion of the quantitative analysis of the student performance data captured through the school's assessment process. Further research can use the three level digital divide framework in learning (theoretical framework developed for this study in Figure 2) as a base and combine it with different analytical lens, which are suitable for quantitative data analysis. This will not just help to validate the three level digital divide framework in learning from the quantitative prospective, but also provide an extension to this research study and contribute to teaching and learning theories.

\section{References}

Anderson, N. (2009). Equity and Information Communication Technology (ICT) in Education (Vol. 6): Peter Lang Publishing Inc., New York.

Baxter, P., \& Jack, S. (2008). Qualitative Case Study Methodology: Study Design and Implementation for Novice Researchers. Qualitative Report, 13(4), 544-559.

Benbasat, I., Goldstein, D. K., \& Mead, M. (1987). The Case Research Strategy in Studies of Information Systems. MIS Quarterly, 11(3), 369-386.

Brake, D. R. (2014). Are We All Online Content Creators Now? Web 2.o and Digital Divides. Journal of Computer-Mediated Communication, 19(3), 591-609. doi: $10.1111 / \mathrm{jcc} 4.12042$ 
Brandtzæg, P. B., Heim, J., \& Karahasanović, A. (2011). Understanding the new digital divide - A typology of Internet users in Europe. International Journal of Human Computer Studies, 69(3), 123-138.

Brosnan, M. J. (1998). The impact of computer anxiety and self-efficacy upon performance. Journal of Computer Assisted Learning, 14(3), 223.

Bru, E. (2006). Factors Associated with Disruptive Behaviour in the Classroom. Scandinavian Journal of Educational Research, 5O(1), 23-43.

Cheung, W. S., \& Hew, K. F. (2009). A review of research methodologies used in studies on mobile

handheld devices in K-12 and higher education settings. Australasian Journal of Educational Technology and Society, 25(2), 153-183.

Cole, J. I. (2001) Surveying the digital future - Year Two: The UCLA Internet Report 2001 Los Angeles, CA: UCLA Center for Communication Policy.

Cook, J., Pachler, N., \& Bachmair, B. (2011). Ubiquitous Mobility with Mobile Phones: A Cultural Ecology for Mobile Learning. E-Learning and Digital Media, 8(3), 181-196.

Cullen, R. (2001). Addressing the digital divide. Online Information Review, 25(5), 311-320.

Demiraslan, Y., \& Usluel, Y. K. (2008). ICT Integration Processes in Turkish Schools: Using Activity Theory to Study Issues and Contradictions. Australasian Journal of Educational Technology, 24(4), 458-474.

Dewan, S., Ganley, D., \& Kraemer, K. L. (2005). Across the Digital Divide: A Cross-Country Multi-Technology Analysis of the Determinants of IT Penetration. Journal of the Association for Information Systems, 6(12), 409-431.

DfES. (2003). 21st century skills : realising our potential : individuals, employers, nation. Retrieved from http://dera.ioe.ac.uk/4747/.

Donohue, G. A., Tichenor, P. J., \& Olien, C. N. (1975). Mass Media and the Knowledge Gap. Communication Research, 2(1), 3-23. doi: doi:10.1177/009365027500200101

Dubé, L., \& Paré, G. (2003). Rigor in Information Systems Positivist Case Research: Current Practices, Trends, and Recommendations. MIS Quarterly, 27(4), 597-636.

Ersanl, C. Y. (2015). The Relationship between Students' Academic Self-efficacy and Language Learning Motivation: A Study of 8th Graders. Procedia - Social and Behavioral Sciences, 199, 472-478. doi: http://dx.doi.org/10.1016/j.sbspro.2015.07.534

Garipagaoglu, B. C. (2013). The effect of self-efficacy on the lifelong learning tendencies of Computer Education and Instructional Technologies students: A case study. 2013, 1O(1), 13 .

Gaziano, C. (2010). Notes on "Revisiting the Knowledge Gap Hypothesis: A Meta-Analysis of Thirty-Five Years of Research.". Journalism \& Mass Communication Quarterly, $87(3 / 4), 615-632$.

Ghobadi, S., \& Ghobadi, Z. (2015). How access gaps interact and shape digital divide: a cognitive investigation. Behaviour \& Information Technology, 34.4, 330-340. doi: 10.1080/0144929X.2013.833650

Gunkel, D. J. (2003). Second thoughts: toward a critique of the digital divide. New Media \& Society, 5(4), 499-522.

Hargittai, E. (2002a). Beyond Logs and Surveys: In-Depth Measures of People's Web Use Skills. Journal of the American Society for Information Science \& Technology, 53(14), 1239-1244. 
Hargittai, E. (2002b). Second-Level Digital Divide: Differences in People's Online Skills. First Monday, 7(4).

Johnson, L., Levine, A., Smith, R., \& Stone, S. (2010). The 2010 Horizon Report. Austin, Texas: The New Media Consortium.

Jones, A., \& Issroff, K. (2007). Motivation and Mobile Devices: Exploring the Role of Appropriation and Coping Strategies. Research in Learning Technology, 15(3), 247-258.

Khalid, M. S., Jurisic, O., Kristensen, H. S., \& Ørngreen, R. (2014). Exploring the use of iPads in Danish Schools. Paper presented at the European Conference on e-Learning.

Lenhart, A., Horrigan, J., Rainie, L., Allen, K., Boyce, A., Madden, M., \& O'Grady, E. (2003) Pew Internet and American Life Project report. Washington, DC: Pew Internet and American Life Project.

Mardis, M., \& Everhart, N. (2013). From Paper to Pixel: The Promise and Challenges of Digital Textbooks for K-12 Schools. In M. Orey, S. A. Jones \& R. M. Branch (Eds.), Educational Media and Technology Yearbook (Vol. 37, pp. pp 93-118). New York: Springer New York.

Martin, A., \& Rader, H. B. (2002). Information and IT literacy : enabling learning in the 21st century / edited by Allan Martin and Hannelore Rader: London : Facet, 2002.

Martin, F., \& Ertzberger, J. (2013). Here and now mobile learning: An experimental study on the use of mobile technology. Comput. Educ., 68, 76-85. doi: 10.1016/j.compedu.2013.04.021

Mass, A. (2011, 27/10/2011). Orewa College iPad plans move ahead, Stuff. Retrieved from http://www.stuff.co.nz/national/education/5859716/Orewa-College-iPad-plans-moveahead

Ministry of Education. (2006). ICT Strategic Framework for Education.: The Ministry of Education, on behalf of the education sector agencies and the National Library of New Zealand.

Moore, C., \& Tasman-Jones, J. (2011, 19/07/2011). School's iPad requirement 'divisive', Stuff. Retrieved from http://www.stuff.co.nz/national/education/5304084/Schools-iPadrequirement-divisive

Murphy, A., Farley, H., Lane, M., Hafeez-Baig, A., \& Carter, B. (2014). Mobile learning anytime, anywhere: What are our students doing? Australasian Journal of Information Systems, 18(3). doi: 10.3127/ajis.v18i3.1098

Newhouse, P., Lane, J., Cooper, M., \& Twining, P. (2014). Redefining education: sustaining 1 to 1 computing strategies in Western Australian schools. Paper presented at the Australian Computers in Education Conference (ACEC).

Pachler, N., Bachmair, B., Cook, J., \& Kress, G. R. (2010). Mobile learning : structures, agency, practices: New York : Springer.

Pachler, N., Cook, J., \& Bachmair, B. (2010). Appropriation of Mobile Cultural Resources for Learning. International Journal of Mobile and Blended Learning, 2(1), 1-21.

Parker, B. (2001). Māori access to information technology / [prepared by Brett Parker, Te Puni Kōkiri]: Wellington, N.Z. : Te Puni Kōkiri/ Ministry of Māori Development, 2001.

Parliament, N. Z. (2017). Oral Questions - Questions to Ministers. New Zealand Parliament.

Parr, M., \& Ward, L. (2005). Evaluation of the digital oppertunities project FarNet: Learning Communities in the Far North. Wellington: Ministry of Education, New Zealand.

Parsons, D. P. (2016). The social surplus of broadband initiatives in compulsory education. Australasian Journal of Information Systems, 20. doi: 10.3127/ajis.v20io.1188 
Partridge, H. (2003). Moving beyond the digital divide: Developing a psychological perspective of digital inequality. In M. Khosrowpour (Ed.), Information Technology and Organizations: Trends, Issues, Challenges and Solutions (Vol. 1, pp. 508-511): Idea Group Inc (IGI).

Parycek, P., Sachs, M., \& Schossböck, J. (2011). Digital Divide among youth: socio-cultural factors and implications. Interactive Technology and Smart Education, 8(3), 161-171. doi: doi:10.1108/17415651111165393

Prestridge, S. (2007). Engaging with the transforming possibilities of ICI: A discussion paper. Australian Educational Computing, 22(2), 3-9.

Rivers, J., \& Rivers, L. (2004). A Summary of the Key Findings of the Evaluations of the Digital Opportunities Pilot Projects (2001 - 2003). Wellington: Ministry of Education, New Zealand.

Sterling, B. (1997). The digital revolution in retrospect. Communications of the ACM, 4O(2), 79-79. doi: 10.1145/253671.253715

Tasman-Jones, J. (2012, 15/05/2012). School iPad revolution may go nationwide, Auckland Now. Retrieved from http://www.stuff.co.nz/auckland/local-news/6919789/SchooliPad-revolution-may-go-nationwide

Van Deursen, A., \& Van Dijk, J. (2014). The digital divide shifts to differences in usage. New Media \& Society, 16(3), 507-526. doi: doi:10.1177/1461444813487959

Van Dijk, J. (2005). The deepening divide : inequality in the information society: Thousand Oaks.

Van Dijk, J. (2006). Digital divide research, achievements and shortcomings. Poetics, 34(4-5), 221-235.

Van Dijk, J., \& Hacker, K. (2003). The Digital Divide as a Complex and Dynamic Phenomenon. Information Society, 19(4), 315.

Vogel-Walcutt, J. J., Gebrim, J. B., Bowers, C., Carper, T. M., \& Nicholson, D. (2011). Cognitive Load Theory vs. Constructivist Approaches: Which Best Leads to Efficient, Deep Learning? Journal of Computer Assisted Learning, 27(2), 133-145.

Warschauer, M. (2003). Technology and social inclusion : rethinking the digital divide.: Cambridge, Mass. : MIT Press, 2003.

Watson, G., \& Prestridge, S. (2003). A networked learning community approach to sustain teacher ICT professional development. Australasian Journal of Educational Technology, 19(2).

Wei, K. K., Teo, H. H., Chan, H. C., \& Tan, B. C. Y. (2011). Conceptualizing and testing a social cognitive model of the digital divide. Information Systems Research, 22(1), 170-187.

Winter, M. (2004). Digital Opportunities Pilot Project (2001-2003) Evaluation of Generation $X P$. Wellington: Ministry of Education, New Zealand.

Wolfswinkel, J. F., Furtmueller, E., \& Wilderom, C. P. M. (2013). Using grounded theory as a method for rigorously reviewing literature. European Journal of Information Systems, 22(1), 45-55. doi: 10.1057/ejis.2011.51

Yin, R. K. (2003). Case Study Research: Design and Methods (3rd ed.). Newbury Park: Sage Publications.

Yoori, H., \& Se-Hoon, J. (2009). Revising the Knowledge Gap Hypothesis: A Meta-Analysis of Thirty-Five Years of Research. Journalism \& Mass Communication Quarterly, 86(3), 513-532. 
Yusuf, M. (2011). The impact of self-efficacy, achievement motivation, and self-regulated learning strategies on students' academic achievement. Procedia-Social and Behavioral Sciences, 15, 2623-2626. doi: http://dx.doi.org/10.1016/j.sbspro.2011.04.158

Zhong, Z. J. (2011). From access to usage: The divide of self-reported digital skills among adolescents. Computers and Education, 56(3), 736-746.

Copyright: (C) 2017 Adhikari, Mathrani \& Scogings. This is an open-access article distributed under the terms of the Creative Commons Attribution-NonCommercial 3.0 Australia License, which permits non-commercial use, distribution, and reproduction in any medium, provided the original author and AJIS are credited.

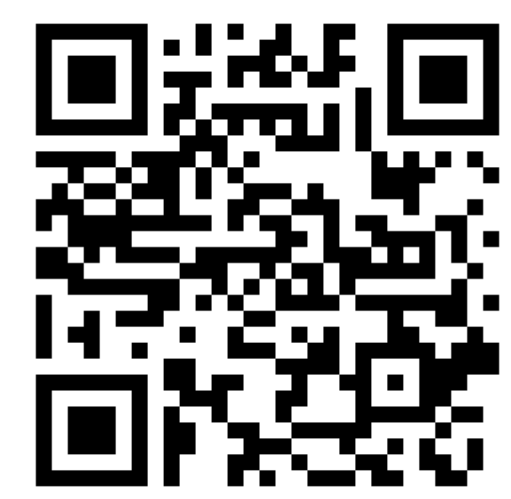

